\title{
An Analysis of the Administrative Agreement on the Beijing-Tianjin-Hebei Region from the Perspective of Law

\author{
Li Feng
}

The Law School of China University of Political Science and Law, Beijing,China,10088

\begin{abstract}
Keywords: Beijing-Tianjin-Hebei; Regional Administrative Agreement; Synergetic Development; Interstate Compacts
\end{abstract}

\begin{abstract}
In the process of promoting the synergetic development of the Beijing-Tianjin-Hebei Region, which is a national strategy, regional administrative agreement has become one of the most important coordination mechanisms of the rule of law. However, at present, the related legislation and legal theories in China fail to give any good response. Through the discussion and analysis of the legal basis, conclusion, legal force and the settlement mechanism of the administrative agreement on the Beijing-Tianjin-Hebei Region, this paper aims to clarify the existing problems and help promote the synergetic development of Beijing, Tianjin and Hebei.
\end{abstract}

\section{Introduction}

In March, 2015, the issuance of the Outline of the Plan for the Coordinated Development of the Beijing-Tianjin-Hebei Region marked the promotion of the synergetic development of the Beijing-Tianjin-Hebei Region became an important national strategy. In the process of implementing this national strategy and by referring to the experience home and abroad, there is no doubt that regional administrative agreement undoubtedly has become the preferred governance instrument under the rule of law. So far, regional administrative agreements that have been concluded on the Beijing-Tianjin-Hebei Region have involved many fields including environment, talent, tourism, culture, agriculture, education, medical care, trade, transportation, science and technology, communication ${ }^{(1)}$ and administration of justice ${ }^{(2)}$, which has laid a solid foundation for the synergetic development of the Beijing-Tianjin-Hebei Region. However, in our country, there has been no good response to the related theories of regional administrative agreements in the jurisprudential circle. For instance, it fails to provide a satisfying answer to the problems including the legal basis, main provisions, procedure of the conclusion, legal force and the settlement of disputes of regional administrative agreement. As a result, the implementation of some regional administrative agreements did not achieve the desired effect. This paper shall focus on the problems mentioned above and make an analysis by combining the particularity of the development of the Beijing-Tianjin-Hebei Region in the hope of doing my bit for the synergetic development of the Beijing-Tianjin-Hebei Region.

\footnotetext{
(1) Integration of the Beijing-Tianjin-Hebei Region Creating the " new capital economic circle"---eBeijing--Beijing Municipal government portal website.

http://zhengwu.beijing.gov.cn/zwzt/jjjyth/

${ }^{2}$ such as Judicial Administration Service Beijing-Tianjin-Hebei Synergetic Development Framework Agreement and Beijing-Tianjin-Hebei Prison Work Synergetic Development and Cooperation Agreement.
} 


\section{The Legal Basis of the Administrative Agreement on the Beijing-Tianjin-Hebei Region}

"Articles of agreement" are explicitly stipulated in Constitution of the US ${ }^{(1)}$ and Articles of Confederation and Perpetual Union also makes formal and specific stipulations on them ${ }^{2}$, which provide a legal basis for interstate agreements. ${ }^{3}$ Although there is no clear and definite provisions on regional administrative agreements in the law of our country, but according to the stipulations in the Constitution of the PRC and the Organic Law of Local People's Congresses at Various Levels and Local People's Governments at Various Levels (hereinafter referred to as the Local Organic Law ), local people's governments above the county level possess the function and power of administrating affairs including economy, education, science, culture, health, sports, environmental and resource protection, urban and rural construction, finance, civil administration, public security, nationalities affairs, judicial administration, supervision and birth control in their own administrative regions and within the limits of authority as prescribed by law. ${ }^{4}$ When a local government conclude a cross-regional administrative agreement related to itself within the limits of functions and powers as stipulated in the Constitution and the Local Organic Law, the conclusion of the agreement should be regarded as having legal basis. "Regional administrative agreement is the legal mechanism based on free will, equality and negotiation. It is different from unilateral decision and does not regard order and obedience as the fundamental elements." ${ }^{(5)}$ In fact, in the process of performing the regional administrative agreement, local governments at different levels all exercise powers and conclude agreements within their territorial jurisdiction, which do not violate the law's restrictions on administrative jurisdiction. Therefore, the conclusion of regional administrative agreements by and between local governments in order to promote the synergetic development of the Beijing-Tianjin-Hebei Region is perfectly reasonable and their subject qualification is flawless.

Besides, seeing from stipulations in the Constitution, the Local Organic Law and the Electoral Law, local governments at the same level enjoy equal legal status, namely regional equality, which is also the externalization and extension of the provision that all men are equal prescribed by the Constitution. At the same time, local government should regard reaching consensus as the principle when arranging regional affairs and dealing with disputes. For instance, Provision 2 of the Article 20 in Environmental Protection Law of the PRC stipulates: " the prevention and control of environmental pollution and ecological damage in the cross-administrative regions excluding those key regions and basins in cross-administrative regions established by the country, the superior people's government shall coordinate and handle that, or the concerned local people's governments shall settle that through negotiation." To sum up, the principle of regional equality and consensus is the basis of rule of law for the conclusion of regional administrative agreement.

\footnotetext{
${ }^{\mathbb{1}}$ According to Article 1, Section 10, item 3 of the Constitution of the US, " without the consent of the Congress, any state shall not levy the tonnage tax, shall not maintain army or warship in time of peace, shall not conclude contracts or treaties with another state or a foreign country, shall not go to war unless it actually suffers invasion or encounter imminent danger."

(2) Section2, Article 6 of Articles of Confederation and Perpetual Union stipulates:" without the consent of the Congress and the statement of the purpose and duration, every two states or more shall not conclude any treaty, confederation or alliance."

${ }^{\circledR}$ See William Kevin Voi , Gary Nit ting . Interstate Compact s \& Agencies .1998 . The Council of State Governments.1999.

(4) See also Article 107 of the Constitution of the PRC and Article 59, Item 5 of the Local Organic Law.

๑ Ye Bifeng,etal, Administrative Agreement---Research on Regional Inter-governmental Cooperation Mechanism. [M]. Law Press China, 2010: 93.
} 


\section{The Conclusion of Administrative Agreement in the Beijing-Tianjin-Hebei Region}

\section{The Procedure of the Conclusion of the Administrative Agreement in the} Beijing-Tianjin-Hebei Region. At present, the most important procedural platform for the Beijing-Tianjin-Hebei Region is joint conference of chiefs, that is to say, members in the region reach a consensus and conclude administrative agreements through the system of regular meetings. On August 2nd, 2014, the State Council set up a leading group and the corresponding office for the synergetic development of the Beijing-Tianjin-Hebei Region, the establishment of this standing body which has decision-making power could make up for the limited time, long interval of the joint conference of chiefs as well as the lack of energy of chiefs. In addition to that, Beijing has also made some breakthrough in the coordination mechanism. For the nine different fields in the synergetic development of the Beijing-Tianjin-Hebei Region, it set up nine special work groups. deputy mayors in charge of the related fields respectively act as the group leaders and group members are made up of the related department heads. Due to the special political status of Beijing, the setup of special groups could more actively and professionally promote the conclusion of the Beijing-Tianjin-Hebei regional administrative agreement. As far as I am concerned, the current overall environment of the Beijing-Tianjin-Hebei Region is suitable for establishing procedural platform similar to the interstate agreements concluded in the US, namely, through negotiation and communication, a consensus is reached in the form of offer and commitment.

Administrative agreements on the Beijing-Tianjin-Hebei Region, if they may break the power balance between the local government and the central government or might damage the interests of the central government, they need the approval of the State Council. If the State Council does not grant approval, the regional administrative agreement shall be null and void. If major affairs in Beijing, Tianjin and Hebei are involved, the agreement shall be submitted to the standing committee of the people's congress in the three places for approval. For other daily routine involving the three places or the dominant affairs in the three places, there is no need for approval, and they just need to be submitted to the State Council and local standing committee of people's congress for the record.

The perfection of the procedure of concluding regional administrative agreement needs to pay attention to public participation, they could participate in the process of agreement conclusion in the way of criticizing and offering suggestions. Administrative organs for concluding the agreement could also listen to public opinions through holding a hearing. Before concluding a regional administrative agreement, administrative organs should fully listen to the opinions of the interest-relevant parties and give them a chance to make a statement and defend themselves.

After a regional administrative agreement is concluded through legal procedures, the agreement text should be made public. In this way, it not only guarantees citizens' right to know, but also allows the public to better supervise the performance of regional administrative agreement. At present, the publicity of administrative agreements on the Beijing-Tianjin-Hebei Region is less than satisfactory. Blanket search has been conducted on the Internet only to find very few agreements with full texts. Most of them are news report, introducing the conclusion background and main content, which is to the disadvantage of the interaction between the public and government, and does not meet the requirement for legality of the procedure of regional administrative agreement either.

Main Clauses of the Administrative Agreement on the Beijing-Tianjin-Hebei Region. Seeing from the practice of the synergetic development of the Beijing-Tianjin-Hebei Region, the operation of the administrative agreement mechanism are still faced with many obstacles, while one of the major reasons for the obstacles is that provisions in the administrative agreement are unduly abstract, dogmatic, impractical and infeasible, so it is hard to guarantee the performance of 
administrative agreement. Related stipulations in the US is relatively mature. Provisions in typical American interstate agreements include elaboration on the purpose, theme and list of goals, statement of the function, power and obligations, substantial regulation, stipulations on administrative organizations or independent regulatory agencies, requirements for financial burden (such as account payable), enforcement or explanation standard and stipulations on taking effect, modification, dropping out, withdrawal or termination. (1) By referring to foreign experience and combining the reality of administrative agreements on the Beijing-Tianjin-Hebei Region, I believe the following main clauses shall be included:

Different from civil contracts, regional administrative agreements are usually bilateral or multilateral, and parties of the agreement tend to conclude package agreements. Since it is necessary to differentiate, the title should be an essential clause. As for administrative agreements on the Beijing-Tianjin-Hebei Region, titles include "agreement” , “framework agreement" , "proposal” and "memorandum”, but most of them are called "framework agreement", such as Beijing-Tianjin-Hebei Synergetic and Innovative Development Strategy study and Basic Research Cooperation Framework Agreement.

Clause about parties of the agreement is an essential provision that stipulates the administrative organ which concludes regional administrative agreement. Among regional administrative agreements in our country, most of them have clauses about parties of the agreements. For instance, Beijing-Tianjin-Hebei Synergetic Development Strategy in the cultural field Framework Agreement stipulates: "under the guidance of the Party committee and governments of various provinces and cities, and through the tripartite negotiation of Beijing Municipal Bureau of Culture, Tianjin Bureau of Culture, Radio, Television and Department of Culture of Hebei Province, the framework agreement shall be concluded."

Purpose clause clarifies the significance of concluding the regional administrative agreement, demonstrating problems that administrative organ hope to solve through concluding the agreement. Clause about fundamental principles identify basic principles regional administrative organs should follow in the process of concluding and performing the agreement. Though the two clauses are important, they need to be short and concise.

Clause about the content of cooperation involves the cooperation arrangement of the regional administrative agreement, rights and obligations of various organs concluding the agreement as well as the specific system design. Thus it is the core and essential clause of regional administrative agreement. For instance, Beijing-Tianjin-Hebei Civil Administration Synergetic Development Cooperation Framework Agreement stipulates matters of cooperation in ten fields including pension service, social organization, social assistance, disaster prevention and reduction as well as funeral and interment management.

At present, Chinese laws have not made stipulations on the way of performing the regional administrative agreement. Therefore, it is necessary to have related stipulations in the agreement, and they will be an essential clause of a regional administrative agreement. Generally speaking, there are two ways of performing regional administrative agreements: performed respectively and performed by an agency. Respective performance is relatively closed, since all parties concerned separately carry out the agreement. It is inconvenient especially when there arise problems calling for cooperation in the process of performing the agreement, but a special agency that performs the agreement will make up for the inconvenience. Thus it is suitable. Many regional administrative

\footnotetext{
(1) F. Zimmerman. Interstate Cooperation: Compact and Administrative Agreements.[M] .Westport.

CT :Greenwood Press. 2002. p53 -57.
} 
agreements in our country also stipulate that they shall be performed by an agency. For instance, part four in Beijing-Tianjin-Hebei Synergetic Development Strategy in the cultural field Framework Agreement makes special stipulations on the strategic cooperation organization mechanism, the establishment of joint conference system as well as the setup of cooperation and coordination group. Besides, it also respectively stipulates matters including the setup, makeup of the joint conference and the cooperation coordination group, holding of the conference in turn and the responsibilities.

Modification and termination clause is of great significance to the development and perfection of regional administrative agreement. Thus it should be an essential clause. However, in practice, few regional administrative agreements make stipulations on their modification and termination. Agreed terms on modification and termination in regional administrative agreement could make parties concerned discover the imperfection in the process of performing the agreement and under specific circumstances, it also provides a basis for administrative organs who conclude the agreement to revise or terminate the agreement. In this way, disputes could be avoided.

Generally speaking, foreign countries have corresponding legal provisions regarding the responsibility for breach of regional administrative agreements and dispute settlement mechanism, so there is no need to specially stipulate that. However, in China, there is no related law to abide by. Therefore, it is necessary to clarify in the agreement. (1) Due to the objective existence of local interests and partial interests, contradiction and conflicts are unavoidable when various parties who conclude the agreement are performing the regional administrative agreement. If they cannot get a proper solution, regional administrative agreement will be a mere scrap of paper. For this reason, it is of great importance to have agreed terms on the responsibility for breach of the agreement and the dispute settlement mechanism.

Seeing from the practice of Beijing-Tianjin-Hebei regional administrative agreement, usually chief executives of the administrative organs that conclude the agreement sign the agreement, which is an essential condition for administrative agreements to be legally effective. The date of signature is an important basis on which to determine the effective date of a regional administrative agreement. Most of the regional administrative agreements in China have no agreed effective date but a date of signature. Therefore, under such circumstances, the date of signature is basically the effective date of the regional administrative agreement.

\section{Legal Force of the Beijing-Tianjin-Hebei Region Administrative Agreement}

Force of regional administrative agreement is the precondition for its performance, which includes the binding force on parties that conclude the agreement and the binding force on the public except the contracting parties. Current laws in China have not made specific and unified regulations on the binding force of regional administrative agreement on its concluding parties, so its binding force mainly comes from the honesty, trustworthiness and credibility of administrative organs which conclude the agreement.

As for the binding force of regional administrative agreement on the public, in the US, apart from the informal administrative agreements, interstate agreements belong to laws and regulations of the state, so of course they could impose direct regulation on the public who are not the parties concluding the agreement. Regional administrative agreements in Spain are different from those in the US, and they do not have the effect of regulation on the public. However, contracting parties

\footnotetext{
(1) Ye Bifeng:" Administrative Agreement against the Background of Regional Economic Integration of Our Country". [J]. Chinese Journal of Law, 2006 (2): 65.

(2) Ye Bifeng:" The Legal Force of Regional Cooperation Agreement", [J]. Jurists Review, 2014 (6): 3.
} 
could set up a joint committee if needed, and the committee could impose regulation on the public according to the law of the administrative organs who conclude the agreement. Regional cooperation agreement in our country is similar to administrative agreement in Spain in terms of the contracting parties and procedure, so it cannot impose direct regulation. The setup and authorized strength of administrative organs in our country are subject to strict restriction, so it is impractical to establish an agency to carry out the regional administrative agreement like Spain. Although the Beijing-Tianjin-Hebei Region is in a special geographic position and the State Council has already set up a leading group and the corresponding office for the synergetic development of the Beijing-Tianjin-Hebei Region, it is, after all, not the special agency to enforce the Beijing-Tianjin-Hebei Region administrative agreement, and its specific responsibilities, functions and power need to be further defined.

As far as I am concerned, at present, practice that is most suitable for Chinese national conditions is that after a regional administrative agreement is concluded, various contracting parties should stipulate the status of the regional administrative agreement in their administrative legislation respectively or joint legislation, or make joint legislation, making coordinated arrangements for public interest and public affairs in the region, or formulate and revise regulations according to regional administrative agreement and also promote the formulation, modification and abolition of local regulations. Another way for the contracting parties to perform the regional administrative agreement is to issue regulatory documents and impose regulation. In this way, regional cooperation agreement possesses the indirect regulating force. What is encouraging is that breakthrough has been made in the Beijing-Tianjin-Hebei Region administrative agreement. For instance, Beijing-Tianjin-Hebei Region Taking the Lead in Making Breakthrough in Environmental Protection Cooperation Framework Agreement makes it clear that under the leadership of the Department of Environmental Protection, the three places shall jointly formulate the Beijing-Tianjin-Hebei Region Environmental Pollution Prevention Regulation, thus realizing the joint legislation. If the Beijing-Tianjin-Hebei Region Environmental Pollution Prevention Regulation is issued and enforced smoothly, it will have a demonstration effect on the performance of regional administrative agreements in other areas.

\section{The Settlement of Disputes about the Beijing-Tianjin-Hebei Region Administrative Agreements}

In the process of performing regional administrative agreement, various disputes will arise inevitably. If they could not get a proper solution, the administrative agreement will become meaningless, and the achievement of regional cooperation wasted. At present, international dispute settlement mechanisms for regional administrative agreement mainly include three kinds, namely, administrative settlement mechanism, arbitral settlement mechanism and judicial settlement mechanism. Seeing from Chinese national conditions, administrative settlement mechanism is the major dispute settlement mechanism for regional administrative agreement, while arbitral settlement mechanism and judicial settlement mechanism are impractical due to the lack of related constitutional and legal basis. However, with the constant perfection of the construction of Chinese legal system, these two will become the future development trend.

Administrative Settlement Mechanism. As for resolution to the disputes of regional administrative agreement, so far there has been no related legal basis available in our country, and in practice, there is no relatively mature and applicable mechanism either. However, regional administrative agreement is concluded by administrative organs that are of equal status, so resolution to their disputes could refer to settlement mechanism for jurisdiction conflicts among the 
administrative organs at the same level. Combining the practice of Beijing-Tianjin-Hebei regional administrative agreement, administrative settlement mechanism could be divided into the following types:

Contracting parties of regional administrative agreement could reach a consensus on the procedure of the administrative resolution to administrative disputes in advance and the related government shall compensate for all the loss arising from the nonperformance or nonfeasance of any party to the agreement. If a consensus could not be reached, the injured party could request the higher authority to get involved and investigate. But unfortunately, such agreed terms are not common in the Beijing-Tianjin-Hebei regional administrative agreements.

Any dispute arising from the performance of regional administrative agreement shall be settled through negotiation between the contracting parties. It is a flexible coordination and settlement mechanism, emphasizing that compromise and consensus should be reached through equal consultations. In the practice of the Beijing-Tianjin-Hebei Region, the consultation could be realized through joint conference of chief executives, cooperation and coordination working group agreed upon in the agreement or setting up a temporary coordination committee. However, this method has its disadvantages too. First of all, whether the contracting parties are willing to negotiate after the dispute arises is unknown. Even if they all agree to negotiate, to reach a compromise may take a long time and cost much, which results in the inefficiency of administration.

This means when dispute arises from the performance of regional administrative agreement, their common higher authority shall adjudicate on it, which is the most common procedure for settling administrative competence dispute in China. (1)Therefore, it should also be the most important mechanism for settling disputes on regional administrative agreement. In fact, the current Constitution of the PRC and Legislation Law of the PRC both confer on higher administrative organs the power to deal with the dispute among subordinate administrative organs. In practice of China, superior and subordinate administrative organs are in a relationship of leading and being led, and its leading idea is order and obedience. Therefore, higher authority's plan for the resolution of dispute on regional administrative agreement is easy to carry out.

The above-mentioned three administrative settlement mechanisms have their advantages and disadvantages. In line with the principle of mutual respect, understanding and accommodation, the contracting parties should choose an appropriate way to settle the dispute properly. However, even if the prior responsibility regulation settlement mechanism and the administrative settlement mechanism ex-post is designed perfectly, still there will arise unsolvable problems. Then it needs to go to the next stage, namely seeking the arbitration of non-administrative organs, such as arbitrary settlement mechanism or judicial settlement mechanism.

Arbitrary Settlement Mechanism. Arbitrary mechanism has the advantages of low charges, simple procedure, loose atmosphere and quick arbitration, so in the early years of America after its foundation, arbitration was widely applied to civil contract dispute. Since the 1920s, it has been widely used in the field of interstate agreement. Since the 1990s, another significant reform has

\footnotetext{
(1) For instance, Article 21 in Administrative Punishment Law of the PRC stipulates:" as for disputes on jurisdiction, submit to their common superior administrative organ to determine the jurisdiction." For another example, Article 24 in Regulations on Letters and Visits stipulates:" petition letters and visits involving two or more administrative organs shall be accepted by the administrative organs involved through consultation; as for dispute on the acceptance, their common superior administrative organ shall decide who should accept the petition."
} 
been made in American administrative procedure. It introduced the "alternative dispute resolution" into administrative process. The Congress successively formulated the Administrative Dispute Resolution Act, Negotiated Rulemaking Act and Alternative Dispute Resolution Act, thus providing a legal basis for the application of arbitration procedure to the resolution of interstate agreement dispute. American experience mentioned above is of great reference significance to the settlement of disputes on regional administrative agreement in China, because regional administrative agreement is a contract in essence. It is the result of the consensus achieved by the administrative organs on an equal footing who conclude the agreement. Arbitration mechanism with many advantages could also apply to regional administrative agreement. Just as the lawsuit system is not exclusive to the field of private law, arbitration, as a dispute settlement mechanism, should not be exclusive to the private law either. Instead, it should serve the whole legal system.

Judicial Settlement Mechanism. Generally speaking, in the process of performing the Beijing-Tianjin-Hebei regional administrative agreement, if any dispute arises, it could be resolved through administrative settlement mechanism. However, based on the principle of " judicial final settlement", if the procedures above have been gone through and parties in dispute still could not arrive at a consensus, judicial procedure shall be resorted to. I suggest the initial right of jurisdiction of the lawsuit related to regional administrative agreement should be conferred on the Higher People's Court in the way of making amendments to the Constitution and in line with the principle of " demandant filing a lawsuit to the court whose jurisdiction the defendant is under", the competent court is thus determined. Indeed, as for the problem of "local protectionism", we should first believe the court will hear the case fairly and justly; in addition, the Supreme People's Court could be appealed to so that it could be solved through the system of the court of second instance being the court of last instance" in Chinese lawsuit system.

\section{References}

[1]YeBifeng.Administrative Agreement---Research on Regional Inter-governmental Cooperation Mechanism[M]. Law Press China, 2010: 93. (In Chinese)

[2] F. Zimmerman. Interstate Cooperation: Compact and Administrative Agreements[M] .Westport. CT :Greenwood Press. 2002.

[3] Integration of the Beijing-Tianjin-Hebei Region Creating the " new capital economic circle"---eBeijing--- Beijing Municipal government portal website. http://zhengwu.beijing.gov.cn/zwzt/jjjyth/ 